\title{
How do age and molecular subtypes impact surgical decisions?
}

\author{
Laura S Dominici ${ }^{1,2,3}$ \& Tari A King*,1,2,3 \\ ${ }^{1}$ Surgical Oncology, Dana-Farber/Brigham \& Women's Cancer Center, Boston, MA 02215, USA \\ ${ }^{2}$ Department of Surgery, Brigham \& Women's Hospital, Boston, MA 02115, USA \\ ${ }^{3}$ Department of Surgery, Harvard Medical School, Boston, MA 02115, USA \\ *Author for correspondence: Tel.: +1 617632 3891; Fax: +1 617632 1930; tking7@bwh.harvard.edu
}

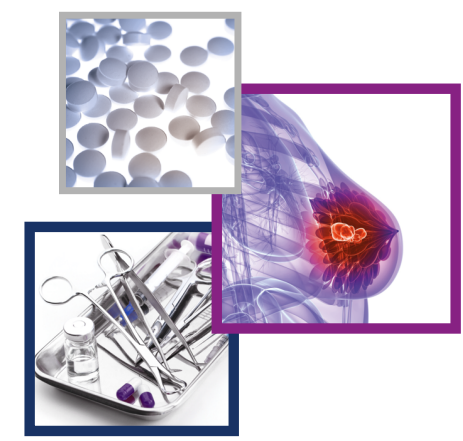

Practice points

- Clinical trials demonstrated equivalent overall survival between breast conservation and mastectomy; however, young age was demonstrated to correlate with higher risk for local recurrence.

- Appropriate systemic therapy is associated with decreased risk of local recurrence in all age groups and subtypes.

- Local recurrence risk in young women has decreased over time largely due to appreciation of the need for appropriate systemic therapy, based on molecular subtype, and young age should not be considered a contraindication to breast conservation.

- Local recurrence risk is similarly impacted by molecular subtype, and there is no difference in locoregional recurrence or survival between breast conservation and mastectomy in older women.

- Rates of local recurrence have decreased over time, largely due to the appropriate use of subtype-directed systemic therapy.

- Although younger patients experience higher rates of local recurrence than their older counterparts, this is largely driven by molecular subtype and is not overcome by choice of surgery (breast conservation or mastectomy).

Tumor molecular subtype and patient age are the predominant drivers of recommendations for systemic therapy in patients with breast cancer. Yet, the impact of these factors on surgical decision-making remains controversial. Younger women often receive the most extensive surgical therapy despite a lack of evidence that bigger surgery translates into better outcomes. In contrast, among older women, there is a desire to minimize local therapy and its associated morbidity. Here, we review contemporary data highlighting the relationship between patient age and breast cancer molecular subtype, and local therapy outcomes. Our perspective is that tumor biology, rather than age, should be the driving factor in determining appropriate local therapy for breast cancer.

First draft submitted: 13 November 2017; Accepted for publication: 12 February 2018; Published online: 09 April 2018

Keywords: axillary lymph nodes $\bullet$ breast cancer $\bullet$ elderly $\bullet$ mastectomy $\bullet$ molecular subtype $\bullet$ surgery $\bullet$ young women

Local therapy plays an important role in staging and treating breast cancer. For patients developing breast cancer at the extremes of age, controversy exists as to the impact of age as well as molecular subtype of tumor on surgical decision making. For younger patients, emphasis has traditionally been focused on aggressive local therapy to minimize locoregional recurrence. In the older cohort, there is motivation to avoid the increased morbidity associated with more extensive local therapy, when it may not impact outcome. Increasingly, tumor biology defines outcomes rather than traditional staging or age. Here, we describe the relationship between age and molecular subtype, review contemporary data related to local therapy outcomes, and discuss future directions for local therapy in breast cancer.

\section{Historical perspective}

Halsted first described the radical mastectomy for management of breast cancer in 1894 [1]. At that time, aggressive local therapy was the only option to improve disease-free and overall survival. Over time, clinical trials initiated 
through the National Surgical Adjuvant Breast and Bowel Project (NSABP) demonstrated the importance of systemic therapy on breast cancer outcomes, and this provided the opportunity to reduce the extent of surgery [2]. The NSABP B06 trial represents the cornerstone in our understanding that survival is equivalent for patients having breast conservation or mastectomy [3]; yet, in the early experience with breast conservation there remained concern over the risk of local recurrence and several groups began to investigate clinical and pathologic factors that predicted for increased risk [4]. Multiple studies identified young age as a risk factor for locoregional failure following breast conservation, leading to controversy about offering this treatment option to young women [5-7]. This was of particular concern in the context of data from the Early Breast Cancer Trialists' Collaborative Group (EBCTCG) suggesting a negative impact of a local recurrence on survival [8]. However, it was also appreciated that younger women were generally under-represented in these studies, making it challenging to draw definitive conclusions.

In older patients, studies sought to allow for de-escalation of aggressive local therapy when appropriate. Older patients with early stage breast cancers often die of other causes [9,10]. Axillary surgery carries less impact on adjuvant therapy recommendations and trials have shown no survival benefit from axillary surgery [11-15]. Data from Cancer and Leukemia Group B (CALGB) 9343 demonstrate no survival advantage for radiation over tamoxifen alone after lumpectomy in women age $\geq 65$ with early stage, hormone receptor-positive cancers. In addition, nearly two-thirds of the women in this trial did not undergo axillary surgery without adverse impact [16,17]. Despite these data, most older women in the USA still appear to be undergoing comprehensive local therapy with axillary surgery and radiation $[18,19]$.

\section{Adjuvant therapy \& local therapy outcomes}

Rates of local recurrence with both breast conservation and mastectomy have decreased over time [20]. Careful tailoring of adjuvant systemic therapy and increasing numbers of targeted agents improve overall outcomes and reduce risk for local recurrence [21]. The addition of HER2-directed therapy has significantly improved overall survival for women with HER2 positive disease, while also significantly reducing rates of local recurrence [22]. These improvements have been most notable for young women, where the addition of appropriate adjuvant systemic therapy halves the rate of local recurrence and the addition of a radiation boost dose to the tumor bed in women undergoing breast conservation further lowers this risk [23-26]. Taken together, these observations demonstrate the relationship between effective systemic therapy, which in the modern era is dictated by tumor biology, and local therapy in determining breast cancer outcomes and highlight the importance of the multidisciplinary team.

\section{Distribution of molecular subtype by age}

Molecular subtype is emerging as the most significant factor driving patient outcome. Younger patients generally have clinically more aggressive tumors (high grade, hormone receptor negative, HER2 positive). This is reflected in the distribution of Oncotype scores with women under 40 having fewer 'low risk' scores and is also reflected in large-scale efforts of molecular subtyping [27-31]; younger women develop fewer true luminal A cancers and may develop more luminal B cancers than older patients [28].

In contrast, although older age is a risk factor for developing breast cancer, older women tend to present with breast cancers with more favorable clinical features (lower grade, hormone receptor positive, HER2 negative) and this is also reflected in studies reporting molecular subtypes among older women [32,33]. In a recent National Comprehensive Cancer Center Network (NCCN) cohort study, which used clinical data obtained from 2000 to 2007 and applied immunohistochemical surrogates to define molecular subtype, women $>70$ years of age had a lower incidence of triple-negative or HER2-positive tumors and a higher incidence of luminal A type cancers [34].

\section{Overall outcome related to molecular subtype $\&$ age}

A retrospective analysis of patients treated in NSABP B-14 demonstrated that younger women who truly have low oncotype scores have similarly favorable outcomes in terms of survival without distant recurrence as do their older counterparts, but this phenotype is only seen in a small percentage of women [35]. Conversely, in a study of over 17,500 women treated at one of eight NCCN cancer centers between 2000 and 2007, women younger than 40 with luminal A or luminal B cancers were more likely to die from breast cancer than older women, but no impact of age on breast cancer-specific survival was seen in triple-negative and HER2-positive cancers [34]. A similar finding was seen in a single institution study from Mexico that found younger women with luminal B tumors had lower overall survival [36]. However, no true molecular subtyping was done to define the cohorts. 
There are still questions as to the complex interactions between age and outcome, particularly around hormone receptor-positive breast cancers in women under 40 years of age. In both young and older women, the challenge is to ensure receipt of adjuvant therapy. Lower compliance with endocrine therapy is seen in the oldest patients treated for breast cancer, which is potentially related to side effects. There is some concern as to whether younger women may receive less benefit from endocrine therapy than older women. Additionally, younger women are less likely to have chemotherapy-induced amenorrhea, which is associated with improved outcomes in hormone receptor positive breast cancers [37]. Young women also appear to be less likely to adhere to endocrine therapy, potentially due to fertility concerns or related to the side effect profile. At the extremes of age, women are also less likely to complete radiation, which has a significant impact on local recurrence risk [38]. These potential barriers to treatment and their impact on risk for systemic and local recurrence need to be recognized and addressed with patients.

In the era of trastuzumab, younger women with HER2-positive breast cancers have similar survival as older women $[34,39]$ and survival in triple-negative breast cancer does not differ by age at diagnosis [39,40]. Worse distantmetastasis free survival was in fact seen in older patients with triple-negative breast cancer or HER2-positive disease compared to luminal subtype, which may be related to omission of therapy [28,41]. A SEER database study which examined patients $\geq 70$ years of age having breast conserving surgery for small hormone receptor-negative tumors from 1998 to 2011 found that receipt of radiation was associated with improvements in 5-year breast cancerspecific survival (93.1 vs $85.0 \%$; $\mathrm{p}<0.01$ ) and overall survival (81.0 vs 61.7\%; p < 0.01) [42]. Another SEER study examining outcomes in patients with triple-negative breast cancer, examined 2017 patients $\geq 70$ years of age compared to 7891 patients $<70$ years of age. In this study, advanced age at diagnosis was associated with worse cancer-specific and overall survival, underuse of adjuvant therapy and underuse of radiation in women with stage II or III disease [43]. These findings are particularly important in light of the fact that older women experience similar benefits in survival and recurrence as younger women when treated with appropriate adjuvant chemotherapy for hormone receptor-negative disease $[44,45]$. Excellent clinical outcomes were also seen in a single-arm study looking at a trastuzumab-based regimen for early stage HER2-positive breast cancers, for which $34 \%$ of the study population was over 60 years of age [46].

Due to comorbidities, many elderly women may not be candidates for chemotherapy. It is important to recognize, however, that omission of therapy may significantly alter outcomes for older women with high-risk disease. In these women, it may be increasingly important to have accurate staging information in order to make decisions around adjuvant therapy. Generally, in the setting of effective systemic therapy, tumor biology appears to be the main driver of outcome rather than age alone.

\section{Local therapy outcomes in the younger patient}

Local control has significantly improved in younger women with breast cancer. Although younger age still correlates with higher likelihood of local regional recurrence, current rates are far lower than seen in previous studies and have decreased over time. A recent population-based study in the Netherlands reported an overall 5-year local recurrence rate of $7.5 \%$ in 1143 women, 40 years of age and under, treated with breast conservation for early stage breast cancer from 1998 to 2010. The risk of local recurrence decreased significantly over time, from $9.8 \%$ for those treated between 1988 and 1998 to 3.3\% for those treated between 2006 and 2010 [24]. A recently published retrospective cohort study using registry data from the European Institute of Oncology examined 1331 consecutive women under 40 years of age who underwent breast conservation between 1997 and 2010 and also reported decreased rates of local recurrence over time. Significant decreases in local recurrence were seen after 2005, which the authors hypothesize correlate to the clinical application of breast cancer molecular subtypes and the introduction of trastuzumab [47]. Similar findings were seen in a retrospective study performed at the Dana-Farber/Harvard Cancer Center in which local recurrence data were collected on 1434 consecutive patients having breast conservation from 1997 to 2006 [48]. In the youngest group of 504 patients (23-46 years of age), cumulative incidence of local recurrence at a median follow-up of 85 months was $5.0 \%$ (cumulative incidence of local recurrence for all patients, $2.1 \%$ ), and these low rates persisted at 106 months of follow-up. For the youngest patients, crude local recurrence rates by subtype included $4.7 \%$ for luminal A; $8.1 \%$ for luminal B; $13.3 \%$ for HER2-positive; and $10.2 \%$ for triple-negative breast cancer. However, none of the patients in this study received anti-HER2 therapy. Increasing numbers of positive nodes and age $\leq 50$ were associated with higher risk of local recurrence, although overall incidence was low as noted above [49].

Locoregional recurrence rates in patients undergoing mastectomy are also low. In a multi-institutional cohort study, Truong et al. reported rates of local recurrence among 1994 patients $\leq 50$ years of age treated with mastectomy 
without radiation for early breast cancer. Rates of local recurrence among all subtypes were low at median follow-up of 4.3 years: $1.3 \%$ for luminal A, 2.3\% for luminal B, $4.6 \%$ for luminal-HER2, 5.6\% for HER2 and 2.2\% for basal-type. Only half the patients in this study received anti-HER2 therapy [50].

In a Dutch study of 1000 women under 35 years of age treated for breast cancer from 2003 to 2008, there were no significant differences in 5 -year rates of local recurrence by subtype; occurring in less than $2 \%$ of hormone receptor-positive disease, regardless of HER2 status, in 5.6\% of hormone receptor-negative/HER2-positive disease and in $4.5 \%$ of triple-negative breast cancer. Equivalent outcomes were also seen when comparing women having breast conserving therapy (BCT) versus mastectomy. For those women having breast conservation, the event rate was so low that evaluation by subtype could not be performed [22]. Rates of local recurrence for patients $<40$ years of age with early-stage breast cancer also did not differ by surgery type in a tumor registry study from Utah. After 2000, rates of local recurrence between breast conservation and mastectomy at 5 years $(3.9 \%$ BCT, $4.8 \%$ mastectomy) and 10 years (6.1\% BCT, 7.9\% mastectomy) were equivalent [51]. There is one recent prospective cohort study, the Prospective study of Outcomes in Sporadic versus Hereditary breast cancer (POSH), that does demonstrate a difference in local control rates for women 18-40 undergoing breast conservation versus mastectomy. Significant differences are seen at both $5(5.3 \%$ BCT, 2.6\% mastectomy; $\mathrm{p}<0.001)$ and 10 years $(11.7 \%$ BCT, $4.9 \%$ mastectomy; $\mathrm{p}<0.001$ ) [52]. Importantly, however, $14 \%$ of patients in the cohort did have BRCA1 or BRCA2 mutations, and local recurrence outcomes have not been examined by mutation status [53]. Further, although the difference in local control between BCT and mastectomy was statistically significant, this study demonstrates acceptably low rates of local recurrence with either surgical approach and did not show any difference in overall survival related to local therapy choice.

Ironically, as the data demonstrate equivalent outcomes between breast conservation and mastectomy, surgical trends demonstrate that increasing numbers of younger women are pursuing bilateral mastectomy [54]. Survival and recurrence are not improved by this approach, but surgical decision making is complex and the subject of ongoing study $[18,55,56]$. The rising rates of bilateral mastectomy are concerning, as there are little data examining long-term quality of life in younger patients who elect to have bilateral mastectomy and reconstruction. Existing information related to patient reported outcomes lacks the follow-up needed to evaluate the long-term impact of these decisions in the youngest patients [57].

\section{Axillary surgery in the younger patient}

Data from recent clinical trials have resulted in de-escalation of extent of axillary surgery in clinically node-negative patients found to have limited axillary nodal involvement at the time of sentinel node biopsy $[1,58]$. Early criticism of the ACOSOG Z0011 trial, which randomized patients with one to two positive sentinel lymph nodes to axillary node dissection or observation, suggested that not enough high risk (age $<50$, triple-negative breast cancer, HER2-positive breast cancer) patients were included in these trials, and physicians were reluctant to omit axillary dissection in these cohorts. However, when patients with high-risk criteria were analyzed in a single institution retrospective study, the majority of them did meet eligibility criteria for ACOSOG Z0011 and were able to avoid axillary dissection without adverse outcome [59]. A similar study looking at 242 women with positive sentinel nodes who would have been candidates for ACOSOG Z0011 and noted to be high risk, based on clinical factors including young age, found that axillary dissection did not impact survival or rates of local recurrence [60].

A primary motivation for both ACOSOG Z0011 and AMAROS, which demonstrated equivalent outcomes between axillary node dissection and axillary radiation, was to minimize risk for morbidity such as lymphedema. Recent work from the Young Women's Cohort study demonstrates that young women experience rates of lymphedema similar to older women and they also report high levels of persistent arm morbidity at 1 year following surgery [61]. The results of ACOSOG Z0011 and AMAROS should be applied to younger women in the same fashion as for older patients. Similarly, younger women should be offered the opportunity to enroll in ongoing trials examining local regional management strategies following preoperative chemotherapy for patients who present with node-positive disease. The Alliance trial (NCT01901094) is examining the role of axillary surgery versus axillary radiation following preoperative chemotherapy for patients who remain node positive after treatment, and the NRG Oncology trial (NCT01872975) is examining the role of regional nodal irradiation following preoperative chemotherapy for those who become pathologically node negative. 


\section{Local therapy outcomes in the older patient}

In general, increasing age is associated with lower risk for local recurrence [48]. As previously noted, the majority of cancers that develop in older women are of the luminal A phenotype, and older patients have fewer triple-negative and HER2-positive tumors [28,62,63]. In patients with favorable subtype tumors, de-escalation of treatment such as omission of radiation and axillary surgery appears to yield acceptably low local recurrence risk [64]. A study of women $>65$ years of age with early breast cancer treated with breast conservation at the Netherlands Cancer Institute found risk of local recurrence to be $2 \%$ at 5 years and $3 \%$ at 10 years, with less than half of these patients receiving endocrine therapy [65]. Arvold et al. also demonstrated low risk of local recurrence for patients aged 64-88 years treated with breast conservation with 5-year cumulative incidence of $0.6 \%$ (95\% CI: $0.1-2.2 \%)$ and when examined by subtype, results were favorable among all groups: $0.4 \%$ for luminal A, $0 \%$ for luminal B, $0 \%$ for HER2-positive and $6.5 \%$ for triple-negative disease [48].

Randomized controlled trials examining omission of radiation in older patients with favorable tumor biology have consistently shown small differences in local control in favor of radiation, with no impact on breast cancerspecific survival or overall survival [8]. The previously mentioned CALGB 9343 trial, with a median follow-up of 12.5 years, reported an absolute decrease in local recurrence of $8 \%$ (10 vs 2\%; $\mathrm{p}<0.01$ ) when radiation was added to lumpectomy and tamoxifen with no significant impact on breast cancer-specific survival or overall survival for women $\geq 70$ years of age with cT1N0 hormone receptor-positive breast cancers [17]. A small absolute decrease in 5 -year risk of local recurrence $(2 \mathrm{vs} 6 \%$; $<0.01$ ) with the addition of radiation was seen in postmenopausal women with tumors $\leq 3 \mathrm{~cm}$ treated with hormonal therapy and surgery in the ABCSG trial [66]. The PRIME II study, included women $\geq 65$ years of age with tumors $\leq 3 \mathrm{~cm}$ treated with breast conserving surgery followed by endocrine therapy with or without radiation and reported similarly low rates of local recurrence ( 1 vs $4 \%$; $\mathrm{p}<0.01)[67]$

\section{Axillary surgery in older women}

Randomized trials examining omission of axillary surgery in the elderly have shown no survival advantage with use of axillary surgery [14,15,68]. The CALGB 9343 trial did not mandate axillary surgery in its eligibility criteria, and nearly two-thirds of enrolled patients did not undergo any node surgery. No significant difference in local recurrence or survival was seen for those patients who did not have axillary surgery [16,17].

Given that data supporting safety of omission of axillary surgery described above as well as the knowledge that axillary staging for older women with early hormone positive breast cancer rarely has significant impact on adjuvant therapy recommendations, older women may be offered breast surgery without axillary staging. This is supported by the American Board of Internal Medicine's Choosing Wisely campaign, which seeks to reduce wasteful medical tests and avoid risks associated with unnecessary procedures [69]. In this campaign, the Society of Surgical Oncology provided a recommendation that sentinel node biopsy need not be routinely performed for women over 70 years of age with hormone positive breast cancer [70]. Surgical management of older women with favorable breast cancers may be offered omission of therapies such as radiation and axillary surgery. In contrast, careful consideration should be given to impact that nodal information may have for treatment decisions in patients with triple-negative or hormone receptor-negative, HER2-positive breast cancers.

\section{Conclusion}

In the modern era, it is our opinion that molecular subtype is the best predictor of outcome, irrespective of age. Contemporary adjuvant therapy has reduced risk for systemic recurrence and also contributes to excellent local control. Even the youngest patients have low rates of local recurrence with modern multimodality treatment and age alone should not be used to recommend more aggressive surgery. In the older patient, consideration can be given to minimizing surgery for those with favorable disease characteristics and in whom there will be little impact on adjuvant therapy recommendations or outcomes. However, in older women with less favorable molecular subtypes, consideration should be given to delivering appropriate surgical intervention and adjuvant therapies, which can absolutely impact disease-related outcome. Ongoing work around the interplay between age, tumor biology, local therapy and outcomes will allow us to continue to refine our surgical approach.

\section{Future perspective}

As additional opportunities for targeted systemic therapies become realized, it is likely that we will continue to see improvements in local control, and that extent of surgery will continue to lessen in significance in terms of 
minimizing risk for disease recurrence. Continued refinement of radiation fields and indications for radiation will be further tailored to risk of recurrence, and potentially by molecular subtype. As such, the complexities of surgical decision-making will become even more important, as will assessing the quality of life outcomes following the various surgical approaches.

Ongoing trials that seek to better identify which patients may be able to de-escalate treatment include the PRECISION trial (NCT02653755), which is currently enrolling women aged 50-75 years who are offered omission of radiation after lumpectomy if molecular subtyping using the PAM50 assay demonstrates low risk disease; LUMINA (NCT01791829), a Canadian trial, which also omits radiation therapy after lumpectomy in women over 55 years of age with hormone receptor-positive early stage disease based upon low risk molecular subtype and Ki67; and in the UK, the PRIMETIME trial (ISRCTN 41579286) omits radiation after lumpectomy based upon biomarker selection for women with early stage, hormone sensitive disease. With respect to nodal surgery, the SOUND (NCT02167490) trial, sponsored by the European Institute of Oncology, randomizes women of any age to sentinel node or observation following negative exam and axillary ultrasound.

Financial \& competing interests disclosure

The authors have no relevant affiliations or financial involvement with any organization or entity with a financial interest in or financial conflict with the subject matter or materials discussed in the manuscript. This includes employment, consultancies, honoraria, stock ownership or options, expert testimony, grants or patents received or pending, or royalties.

No writing assistance was utilized in the production of this manuscript.

Open access

This work is licensed under the Creative Commons Attribution 4.0 License. To view a copy of this license, visit http://creativecomm ons.org/licenses/by/4.0/

\section{References}

Papers of special note have been highlighted as: • of interest; $\bullet \bullet$ of considerable interest

1. Ghossain A, Ghossain MA. History of mastectomy before and after Halsted. J. Med. Liban. 57(2), 65-71 (2009).

2. Wickerham DL, O'Connell MJ, Costantino JP et al. The half century of clinical trials of the National Surgical Adjuvant Breast and Bowel Project. Semin. Oncol. 35(5), 522-529 (2008).

3. Fisher B, Anderson S, Bryant $\mathrm{J}$ et al. Twenty-year follow-up of a randomized trial comparing total mastectomy, lumpectomy and lumpectomy plus irradiation for the treatment of invasive breast cancer. N. Engl. J. Med. 347(16), 1233-1241 (2002).

4. Clarke DH, Martinez AA. Identification of patients who are at high risk for locoregional breast cancer recurrence after conservative surgery and radiotherapy: a review article for surgeons, pathologists and radiation and medical oncologists. J. Clin. Oncol. 10(3), 474-483 (1992).

5. Recht A, Connolly JL, Schnitt SJ et al. The effect of young age on tumor recurrence in the treated breast after conservative surgery and radiotherapy. Int. J. Radiat. Oncol. Biol. Phys. 14(1), 3-10 (1988).

6. Fourquet A, Campana F, Zafrani B et al. Prognostic factors of breast recurrence in the conservative management of early breast cancer: a 25-year follow-up. Int. J. Radiat. Oncol. Biol. Phys. 17(4), 719-725 (1989).

7. Vilcoq JR, Calle R, Stacey P, Ghossein NA. The outcome of treatment by tumorectomy and radiotherapy of patients with operable breast cancer. Int. J. Radiat. Oncol. Biol. Phys. 7(10), 1327-1332 (1981).

8. Darby S, McGale P, Correa C et al. Effect of radiotherapy after breast-conserving surgery on 10-year recurrence and 15 -year breast cancer death: meta-analysis of individual patient data for 10,801 women in 17 randomized trials. Lancet 378(9804), 1707-1716 (2011).

9. Schonberg MA, Marcantonio ER, Ngo L, Li D, Silliman RA, McCarthy EP. Causes of death and relative survival of older women after a breast cancer diagnosis. J. Clin. Oncol. 29(12), 1570-1577 (2011).

10. Satariano WA, Ragland DR. The effect of comorbidity on 3-year survival of women with primary breast cancer. Ann. Intern. Med. 120(2), 104-110 (1994).

11. Giuliano AE, Hunt KK, Ballman KV et al. Axillary dissection vs no axillary dissection in women with invasive breast cancer and sentinel node metastasis: a randomized clinical trial. JAMA 305(6), 569-575 (2011).

12. Giuliano AE, Ballman K, McCall L et al. Locoregional recurrence after sentinel lymph node dissection with or without axillary dissection in patients with sentinel lymph node metastases: long-term follow-up from the American College of Surgeons Oncology Group (Alliance) ACOSOG Z0011 randomized trial. Ann. Surg. 264(3), 413-420 (2016).

13. Galimberti V, Cole BF, Zurrida $S$ et al. Axillary dissection versus no axillary dissection in patients with sentinel-node micrometastases (IBCSG 23-01): a Phase III randomized controlled trial. Lancet Oncol. 14(4), 297-305 (2013). 
14. Martelli G, Miceli R, Costa A et al. Elderly breast cancer patients treated by conservative surgery alone plus adjuvant tamoxifen: fifteen-year results of a prospective study. Cancer 112(3), 481-488 (2008).

15. Martelli G, Boracchi P, Ardoino I et al. Axillary dissection versus no axillary dissection in older patients with T1N0 breast cancer: 15-year results of a randomized controlled trial. Ann. Surg. 256(6), 920-924 (2012).

16. Hughes KS, Schnaper LA, Berry D et al. Lumpectomy plus tamoxifen with or without irradiation in women 70 years of age or older with early breast cancer. N. Engl. J. Med. 351(10), 971-977 (2004).

17. Hughes KS, Schnaper LA, Bellon JR et al. Lumpectomy plus tamoxifen with or without irradiation in women age 70 years or older with early breast cancer: long-term follow-up of CALGB. J. Clin. Oncol. 9343.c 31(19), 2382-2387 (2013).

-. This cooperative group trial demonstrated safety of omission of radiation and axillary surgery in women over 70 years of age with early, hormone-positive breast cancer.

18. Pesce C, Czechura T, Winchester DJ, Huo D, Winchester DP, Yao K. Axillary surgery among estrogen receptor positive women 70 years of age or older with clinical stage I breast cancer, 2004-2010: a report from the National Cancer Data Base. Ann. Surg. Oncol. 20(10), 3259-3265 (2013).

19. Rutter CE, Lester-Coll NH, Mancini BR et al. The evolving role of adjuvant radiotherapy for elderly women with early-stage breast cancer. Cancer 121(14), 2331-2340 (2015).

20. Aalders KC, Van Bommel AC, Van Dalen T et al. Contemporary risks of local and regional recurrence and contralateral breast cancer in patients treated for primary breast cancer. Eur. J. Cancer 63, 118-126 (2016).

21. Cabioglu N, Hunt KK, Buchholz TA et al. Improving local control with breast-conserving therapy: a 27-year single-institution experience. Cancer 104(1), 20-29 (2005).

22. Aalders KC, Postma EL, Strobbe LJ et al. Contemporary locoregional recurrence rates in young patients with early-stage breast cancer. $J$. Clin. Oncol. 34(18), 2107-2114 (2016).

-• Contemporary rates of local recurrence in young patients with early breast cancer are low.

23. Van Der Sangen MJ, Van De Wiel FM, Poortmans PM et al. Are breast conservation and mastectomy equally effective in the treatment of young women with early breast cancer? Long-term results of a population-based cohort of 1,451 patients aged $\leq 40$ years. Breast Cancer Res. Treat. 127(1), 207-215 (2011).

24. Van Laar C, Van Der Sangen MJ, Poortmans PM et al. Local recurrence following breast-conserving treatment in women aged 40 years or younger: trends in risk and the impact on prognosis in a population-based cohort of 1143 patients. Eur. J. Cancer 49(15), 3093-3101 (2013).

25. Bartelink H, Horiot JC, Poortmans PM et al. Impact of a higher radiation dose on local control and survival in breast-conserving therapy of early breast cancer: 10-year results of the randomized boost versus no boost EORTC 22881-10882 trial. J. Clin. Oncol. 25(22), 3259-3265 (2007).

26. Jones HA, Antonini N, Hart AA et al. Impact of pathological characteristics on local relapse after breast-conserving therapy: a subgroup analysis of the EORTC boost versus no boost trial. J. Clin. Oncol. 27(30), 4939-4947 (2009).

27. Swain SM, Nunes R, Yoshizawa C, Rothney M, Sing AP. Quantitative gene expression by recurrence score in ER-positive breast cancer, by age. Adv. Ther. 32(12), 1222-1236 (2015).

28. Jenkins EO, Deal AM, Anders CK et al. Age-specific changes in intrinsic breast cancer subtypes: a focus on older women. Oncologist 19(10), 1076-1083 (2014).

29. Copson E, Eccles B, Maishman T et al. Prospective observational study of breast cancer treatment outcomes for UK women aged 18-40 years at diagnosis: the POSH study. J. Natl Cancer Inst. 105(13), 978-988 (2013).

30. Van De Vijver MJ, He YD, Van't Veer LJ et al. A gene-expression signature as a predictor of survival in breast cancer. $N$. Engl. J. Med. 347(25), 1999-2009 (2002).

31. Collins LC, Marotti JD, Gelber $S$ et al. Pathologic features and molecular phenotype by patient age in a large cohort of young women with breast cancer. Breast Cancer Res. Treat. 131(3), 1061-1066 (2012).

32. Carey LA, Perou CM, Livasy CA et al. Race, breast cancer subtypes and survival in the Carolina Breast Cancer Study. JAMA 295(21), 2492-2502 (2006).

33. Cancello G, Maisonneuve P, Rotmensz N et al. Prognosis and adjuvant treatment effects in selected breast cancer subtypes of very young women (<35 years) with operable breast cancer. Ann. Oncol. 21(10), 1974-1981 (2010).

34. Partridge AH, Hughes ME, Warner ET et al. Subtype-dependent relationship between young age at diagnosis and breast cancer survival. J. Clin. Oncol. 34(27), 3308-3314 (2016).

-• Effect of age on survival of women with early breast cancer varies by subtype.

35. Paik S, Shak S, Tang G et al. A multigene assay to predict recurrence of tamoxifen-treated, node-negative breast cancer. N. Engl. J. Med. 351(27), 2817-2826 (2004).

36. Villarreal-Garza C, Mohar A, Bargallo-Rocha JE et al. Molecular subtypes and prognosis in young Mexican women with breast cancer. Clin. Breast Cancer 17(3), e95-e102 (2017). 
37. Walshe JM, Denduluri N, Swain SM. Amenorrhea in premenopausal women after adjuvant chemotherapy for breast cancer. J. Clin. Oncol. 24(36), 5769-5779 (2006).

38. Freedman RA, Fedewa SA, Punglia RS et al. Factors associated with radiation therapy incompletion for patients with early-stage breast cancer. Breast Cancer Res. Treat. 155(1), 187-199 (2016).

39. Sheridan W, Scott T, Caroline $S$ et al. Breast cancer in young women: have the prognostic implications of breast cancer subtypes changed over time? Breast Cancer Res. Treat. 147(3), 617-629 (2014).

40. Radosa JC, Eaton A, Stempel M et al. Evaluation of local and distant recurrence patterns in patients with triple-negative breast cancer according to age. Ann. Surg. Oncol. 24(3), 698-704 (2017).

-. Young age at diagnosis is not an independent predictor of local recurrence in women with triple-negative breast cancer.

41. Konigsberg R, Pfeiler G, Hammerschmid N et al. Breast cancer subtypes in patients aged 70 years and older. Cancer Invest. 34(5), 197-204 (2016).

42. Daugherty EC, Daugherty MR, Bogart JA, Shapiro A. Adjuvant radiation improves survival in older women following breast-conserving surgery for estrogen receptor-negative breast cancer. Clin. Breast Cancer 16(6), 500e502-506e502 (2016).

43. Zhu W, Perez EA, Hong R, Li Q, Xu B. Age-related disparity in immediate prognosis of patients with triple-negative breast cancer: a population-based study from SEER Cancer Registries. PLoS ONE 10(5), e0128345 (2015).

44. Muss HB, Woolf S, Berry D et al. Adjuvant chemotherapy in older and younger women with lymph node-positive breast cancer. JAMA 293(9), 1073-1081 (2005).

45. Giordano SH, Duan Z, Kuo YF, Hortobagyi GN, Goodwin JS. Use and outcomes of adjuvant chemotherapy in older women with breast cancer. J. Clin. Oncol. 24(18), 2750-2756 (2006).

46. Tolaney SM, Barry WT, Dang CT et al. Adjuvant paclitaxel and trastuzumab for node-negative, HER2-positive breast cancer. $N$. Engl. J. Med. 372(2), 134-141 (2015).

47. Botteri E, Veronesi $\mathrm{P}$, Vila J et al. Improved prognosis of young patients with breast cancer undergoing breast-conserving surgery. Br. J. Surg. 104(13), 1802-1810 (2017).

48. Arvold ND, Taghian AG, Niemierko A et al. Age, breast cancer subtype approximation, and local recurrence after breast-conserving therapy. J. Clin. Oncol. 29(29), 3885-3891 (2011).

49. Braunstein LZ, Taghian AG, Niemierko A et al. Breast-cancer subtype, age, and lymph node status as predictors of local recurrence following breast-conserving therapy. Breast Cancer Res. Treat 161(1), 173-179 (2017).

-• Local recurrence rates are very low for the majority of patients undergoing breast conserving therapy for patients with breast cancer.

50. Truong PT, Sadek BT, Lesperance MF et al. Is biological subtype prognostic of locoregional recurrence risk in women with pT1-2N0 breast cancer treated with mastectomy? Int. J. Radiat. Oncol. Biol. Phys. 88(1), 57-64 (2014).

51. Frandsen J, Ly D, Cannon G et al. In the modern treatment era, is breast conservation equivalent to mastectomy in women younger than 40 years of age? a A multi-institution study. Int. J. Radiat. Oncol. Biol. Phys. 93(5), 1096-1103 (2015).

52. Maishman T, Cutress RI, Hernandez A et al. Local recurrence and breast oncological surgery in young women with breast cancer: The POSH Observational Cohort Study. Ann. Surg. 266(1), 165-172 (2017).

53. Eccles DM, Copson ER, Maishman T et al. Does BRCA status affect outcome in young breast cancer patients? Results from the prospective study of outcomes in sporadic and hereditary breast cancer (POSH). Presented at: 39th San Antonio Breast Cancer Symposium. San Antonio, TX, USA, 7 December, 2016.

54. Nash R, Goodman M, Lin CC et al. State variation in the receipt of a contralateral prophylactic mastectomy among women who received a diagnosis of invasive unilateral early-stage breast cancer in the United States, 2004-2012. JAMA Surg. 152(7), 648-657 (2017).

55. Wong SM, Freedman RA, Sagara Y, Aydogan F, Barry WT, Golshan M. Growing use of contralateral prophylactic mastectomy despite no improvement in long-term survival for invasive breast cancer. Ann. Surg. 265(3), 581-589 (2017).

- Young women undergo high rates of contralateral prophylactic mastectomy with no significant improvement in survival.

56. Rosenberg SM, Partridge AH. Contralateral prophylactic mastectomy: an opportunity for shared decision making. JAMA Surg. 149(6), 589-590 (2014).

57. Pusic AL, Matros E, Fine $\mathrm{N}$ et al. Patient- reported outcomes 1 year after immediate breast reconstruction: results of the Mastectomy Reconstruction Outcomes Consortium Study. J. Clin. Oncol. 35(22), 2499-2506 (2017).

58. Donker M, Van Tienhoven G, Straver ME et al. Radiotherapy or surgery of the axilla after a positive sentinel node in breast cancer (EORTC 10981-22023 AMAROS): a randomised, multicentre, open-label, Phase 3 non-inferiority trial. Lancet Oncol. 15(12), 1303-1310 (2014).

59. Chung A, Gangi A, Mirocha J, Giuliano A. Applicability of the ACOSOG Z0011 criteria in women with high-risk node-positive breast cancer undergoing breast conserving surgery. Ann. Surg. Oncol. 22(4), 1128-1132 (2015).

60. Mamtani A, Patil S, Van Zee KJ et al. Age and receptor status do not indicate the need for axillary dissection in patients with sentinel lymph node metastases. Ann. Surg. Oncol. 23(11), 3481-3486 (2016). 
61. Kuijer A, Dominici LS, Rosenberg SM et al. Risk of arm morbidity after local therapy in young breast cancer survivors. Presented at: 40th San Antonio Breast Cancer Symposium. San Antonio, TX, USA, 8 December 2017.

62. Anderson WF, Katki HA, Rosenberg PS. Incidence of breast cancer in the United States: current and future trends. J. Natl Cancer Inst. 103(18), 1397-1402 (2011).

63. De Munck L, Schaapveld M, Siesling $S$ et al. Implementation of trastuzumab in conjunction with adjuvant chemotherapy in the treatment of non-metastatic breast cancer in The Netherlands. Breast Cancer Res. Treat. 129(1), 229-233 (2011).

64. Van De Water W, Bastiaannet E, Scholten AN et al. Breast-conserving surgery with or without radiotherapy in older breast patients with early stage breast cancer: a systematic review and meta-analysis. Ann. Surg. Oncol. 21(3), 786-794 (2014).

65. Van Der Leij F, Van Werkhoven E, Bosma $S$ et al. Low risk of recurrence in elderly patients treated with breast conserving therapy in a single institute. Breast 30, 19-25 (2016).

-• Postoperative radiation for women 65 years of age or older undergoing breast conserving surgery and endocrine therapy results in modest reduction in local recurrence at 5 years.

66. Pötter R, Gnant M, Kwasny W et al. Lumpectomy plus tamoxifen or anastrozole with or without whole breast irradiation in women with favorable early breast cancer. Int. J. Radiat. Oncol. Biol. Phys. 68(2), 334-340 (2007).

67. Kunkler IH, Williams LJ, Jack WJ, Cameron DA, Dixon JM, Investigators PI. Breast-conserving surgery with or without irradiation in women aged 65 years or older with early breast cancer (PRIME II): a randomized controlled trial. Lancet Oncol. 16(3), 266-273 (2015)

68. Martelli G, Boracchi P, De Palo M et al. A randomized trial comparing axillary dissection to no axillary dissection in older patients with T1N0 breast cancer: results after 5 years of follow-up. Ann. Surg. 242(1), 1-6; discussion 7-9 (2005).

69. Medicine ABOI. www.choosingwisely.org/

70. Choosing Wisely. Don't routinely use sentinel node biopsy in clincally node negative women $\geq 70$ years of age with hormone receptor positive invasive breast cancer. www.choosingwisely.org/clinician-lists/sso-sentinel-node-biopsy-in-node-negative-women-70-and-over/ 
